Mientras Pedro preparaba la ensalada, Marina introducía el jamón al horno. "¿Por qué le cortaste las puntas al jamón?" le preguntó él. Marina lo miró pensativa por unos segundos sin responder. "No sé, se cocinará mejor creo, en realidad siempre vi a mi mamá hacerlo así". Esa noche celebraban Navidad y la mamá de Marina estaba presente, durante la cena ella le preguntó: "¿Mamá, por qué siempre le cortabas las puntas al jamón antes de ponerlo en el horno?", "¡Ah!, es una cosa que aprendí de mamá". Como la abuela estaba presente casi a coro le preguntaron por qué lo hacía así; la abuela le respondió casi con nostalgia mientras se llevaba el tenedor a la boca: "Yo se las cortaba siempre porque nunca tuve un molde lo suficientemente grande como para que me cupiera el jamón entero". ${ }^{1}$

Me gusta abrir la primera sesión de mi clase de Roles Sexuales cada trimestre con esta anécdota porque es un ejemplo de cómo, igual que Marina o su madre, interiorizamos y adoptamos modelos de comportamiento observados a nuestro alrededor sin cuestionarnos sobre la validez de los mismos para nuestras vidas.

¿Cuántas veces nos hemos impuesto acciones y actitudes y nos hemos cohibido de otras porque "no son propias de nuestro sexo"? ¿Cuántas niñas han sido regañadas por sentarse con las piernas entreabiertas o jugar pelota "porque eso es de varones"? ¿Cuántos niños juegan muñecas escondidos porque lo tienen prohi- 
bido? ¿Y cuántos se contienen el llanto porque "los hombres no lloran"?

Decimos "las cosas tienen que ser así porque siempre han sido así y por algo será". "No se puede ir en contra de lo 'naturai' $(? !) "$.

Así, como enunciara un político norteamericano de la década de los 60: "El gran enemigo de la verdad es muy a menudo no la mentira, deliberada y deshonesta; sino el mito, persistente, persuasivo e irrealista. Demasiado a menudo nos apegamos rápidamente a los clichés de nuestros antepasados. Encajamos todas las evidencias a esquemas de interpretaciones prefabricadas. Disfrutamos el confort de la opinión sin el disconfort del pensamiento". ${ }^{2}$

Los trabajos sobre la problemática genérica de teóricas e investigadoras de diversas áreas del saber como Margaret Mead y Simone de Beauvoir, hicieron evidente en las décadas de 1930 y 1940 la necesidad de entender las diferencias entre los sexos dentro del contexto social en que las mismas se originan.

Más aún llegaron a demostrar a través de estudios trarisculturales, históricos, sociológicos y psico-sociales que las diferencias tan marcadas entre los sexos que se observan en sociedades como la nuestra son el producto de normas sociales que se imponen a través de la socialización sobre mujeres y hombres para lograr como resultado seres femeninos y masculinos en función del sexo. Dos fórmulas únicas, rígidas y mutuamente excluyentes de seres con características casi antagónicas (supuestamente "complementarias"), con la vida predeterminada al nacer en cuanto a expectativas, roles, valorizaciones, status, formas de comportamiento y rasgos de personalidad manifiestos en todos los órdenes: "público" y "privado" (en el trabajo remunerativo, en el trabajo doméstico, estudio, diversiones, relaciones, sexualidad, etc. etc.).

Contradictoriamente, algo como el sexo que resulta tan obvio a una persona desde muy temprana edad ${ }^{3}$ se le atribuyen socialmente dos modelos complejos que cruzan todos los aspectos de la vida y que significará años de aprendizaje permanente, y "premios" y "castigos" de por vida que contribuiran a mantener los patrones aprendidos.

Así, no basta con ser mujer o ser hombre y ser capaz de reconocer las diferencias biológicas que lo determinan. Es necesario aprender a pensar, a sentir y a comportarse de manera diferenciada y correspondiente en función de' los genitales con que la suerte nos obsequiara." Habrá que colocarse en las espaldas las correspondientes pesadas "mochilas" rosadas o azules y vivir nuestras vidas en función. del contenido "apropiado" a una u otra 
que se nos va (y posteriormente vamos) introduciendo en las mismas.

Legitimando las diferencias entre los sexos se legitima también la jerarquía entre los hombres y las mujeres.

Las diferencias reales intrínsecas a los sexos, originadas en el par de cromosomas sexual ( $x$ x y $x y$ ) se traducen únicamente a nivel de ciertos rasgos cerebrales, de órganos sexuales, en la concentración hormonal en la sangre y en características físicas secundarias que varían dentro de un continuo para las mujeres y para los hombres cruzándose ambas curvas. ${ }^{5}$

¿Qué podrán significar esas diferencias biológıcas más allá de la acción de reproducirse? ¿O de ciertas habilidades que presentan tendencias de un desarrollo mayor como la habilidad espacial-visual en los hombres y la habilidad verbal en las mujeres? $Y$ aun éstas presentan curvas de frecuencia que se cruzan entre los sexos. ¿Qué otras diferencias de base biológica existen entre hombres y mujeres y qué implican las mismas en lo social?... No ha podido determinarse. ¿Y hasta dónde el hecho mismo de plantear esa pregunta e insistir empecinadamente en lograr posibles respuestas no estará siendo reflejo de una ideología patriarcal que busca mecanismos científicos para mantener la jerarquía entre los sexos?

El hablar erróneamente desde toda perspectiva, particularmente desde la biológica, de sexos contrarios u opuestos en lugar de sexos diferentes, servirá de postulado básico para la existencia y reproducción de los códigos genéricos masculino y femenino. Estos códigos sociales determinan lo propio y lo impropio para cada sexo de manera exógena, arbitraria, impuesta. A través de mecanismos como discriminaciones y desventajas sociales, percepciones deformadas, y hartos mitos y prejuicios se obtendrá el producto deseado en toda sociedad patriarcal: seres humanos radicalmente diferentes en función de su sexo. Lo cual, paradójicamente vendrá a justificar la ideología que le da origen.

Desde la década de los 60 y sobre todo en las dos últimas décadas, el estudio de género constituye toda un área de investigación y reflexír que enmarca el trabajo de muchas mujeres y hombres en diversas áreas del conocimiento, particularmente: sociología, antropología, psicología y economía; aunque otros campos están también analizando este problema desde sus perspectivas.

La producción es vasta en cada una de las áreas que enfocan la cuestión genérica.

Las universidades y centros de investigación social promueven 
y apoyan esta línea de trabajo concientes de su importancia para lograr una comprensión más adecuada de la sociedad en su conjunto. Esto se ha dado sobre todo en Estados Unidos y en Europa, pero en la última década se ha hecho extensivo a América Latina y El Caribe, Australia y a algunos países de Africa y de Asia.

Sin embargo, el estudio de género por referirse a una realidad tan cercana a todas y a todos, de una importancia "vertebral" en nuestras vidas e interiorizado tan profundamente, es un área del conocimiento que recibe una enorme resistencia de profesores(as) y estudiantes dentro del contexto académico, como "dignos" representantes en su ambiente de la sociedad en su conjunto.

La óptica de género lejos de adoptarse por los y las docentes en muchos de los cursos de las distintas carreras queda en el olvido, en la invisibilidad, no mencionada o planteada superficialmente en muchos casos a manera de opiniones personales (en su mayoría producto de prejuicios y desinformación).

Si se pretende formar profesionales en lugar de técnicos(as); dejar de lado la cuestión de género es una deficiencia imperdonable, dado que la misma tiñe y en gran medida determina las vidas del $100 \%$ de la población mundial.

A partir de esta preocupación diseñamos para el INTEC el curso "Psicología de los Roles Sexuales" como una electiva fija de la carrera de psicología, abierta a las(os) estudiantes de las demás carreras de Sociales y de las otras facultades (Medicina e Ingeniería).

La Ilamamos Roles "Sexuales" para dar idea del contenido a un público no entrenado en este campo, pero toda la materia se refiere al estudio de género; y no sólo desde la perspectiva de las corrientes psicológicas más importantes, sino que también se enfoca el desarrollo de los roles de género a partir de la biología, la antropología y la sociología. (Ver Programa del Curso -Anexo 1-).

Desde 1987 se ofrece dos veces al año, en los trimestres abril-junio y octubre-diciembre. Al momento se ha impartido en 3 ocasiones, habiéndola cursado unos 100 estudiantes en su mayoría de Ciencias Sociales. La proporción de mujeres a hombres ha sido constante en las tres experiencias, de aproximadamente 3.5 o 4 a 1 respectivamente. Estos números reflejan la proporción actual de estudiantes de un sexo y otro en la carrera de psicología que es el público fundamental de esta materia, de manera que no creemos que tal relación sea indicador de una resistencia mayor de parte de los hombres a cursar Psicología de los Roles Sexuales.

El curso tiene por objetivos: aportar datos, informaciones y 
explicaciones que ofrecen las diferentes disciplinas que estudian el problema de género; aclarar conceptos básicos en esta área como: sexo, género, patriarcado, sexismo, feminismo, socialización, estereotipos, prejuicios, profecías de autorrealización, percepciones deformadas, etc.; y especialmente se busca promover entre el alumnado la conciencia de la existencia en nuestra sociedad y en la mayoría de las otras de una jerarquía entre los sexos que les lleve a incluir en sus trabajos y análisis la problemática genérica - que incluso sea esta preocupación motor de esfuerzos futuros de investigación y trabajo desde sus disciplinas.

Las y los estudiantes que han cursado la materia, muchas(os) como oyentes, han demostrado un gran interés y entusiasmo en el tema a través de una asistencia masiva permanente a lo largo del trimestre (siendo ésta libre); en una intensa participación en clase; en la calidad de los trabajos que les son asignados; y en la pena que en su mayoría manifiestan cuando el curso termina!

Entre muchos(as) de los(as) estudiantes que han tomado Psicología de los Roles Sexuales se ha notado un interés sostenido en esta problemática después de finalizado el curso. Esto es posible notarlo a partir de su asistencia a actividades de divulgación científica sobre la situación de la mujer (charlas, talleres, conferencias, etc.); a través de una oleada permanente de estas(os) estudiantes a la oficina de Estudios de la Mujer del EQUIS-INTEC solicitando asesoría para realizar proyectos de investigación que ellas(os) han propuesto en otros cursos abordando la problemática genérica, otros(as) pasan por la oficina a informarse de actividades que se vayan a realizar en INTEC o cualquier otro Centro a propósito del tema y algunas(os) a ofrecer su colaboración para cualquier actividad programada por Estudios de Mujer. A veces vienen a traer y comentar recortes de periódicos (desde artículos hasta muñequitos) que les parecieran interesantes y relacionados a patrones genéricos o movimientos sociales para el cambio de los mismos. Hay quienes acuden sencillamente a leer el mural de la oficina y a contar experiencias' personales que "post-Psicología de los Roles Sexuales" analizan bajo una perspectiva genérica.

Tres testimonios sobre cómo las(os) estudiantes evalúan el curso para sí recuerdo con particular vividez:

Sofía (estudiante de administración de empresas: "Menos mal que cogí esta materia ahora que mi hija tiene 3 meses, si tuviera ya tres años tal vez sería demasiado tarde para tratar de educarla de una manera más libre y respetuosa de su individualidad".

Oscar (estudiante de economía): "Antes yo no leía ni loco un libro o un artículo de economía escrito por una mujer, bueno... sólo de Joan Robinson porque es una genio y aun con ella trataba 
de abstraerme del hecho de que es mujer; ahora pienso que tengo mucho material por descubrir y mucho que pensar".

Virginia (estudiante de psicología): "Tengo 2 hijos y 1 hija adolescentes, al principio del curso y cada vez más mientras avanzaba, me preguntaba si todavía estaría a tiempo de enseñarles a ser más flexibles con los patrones de género y a predicarles la igualdad con el ejemplo de mi trato. Hoy que el curso termina me encuentro preguntándome si todavía estaré a tiempo YO de aprender esas cosas y vivirlas para mí. Quiero hacerlo. Necesito hacerlo".

Con el ánimo de hacer más dinámico y activo el proceso de aprendizaje, y de acuerdo con Paulo Freire en que: "Nadie enseña a nadie, y nadie aprende solo. La gente se educa mutuamente y en interacción con el medio", la metodología que se utiliza en este curso requiere además de exposiciones de la profesora, de lecturas y de la discusión en grupo de ambas, de la realización de ejercicios que varían de trimestre a trimestre.

Los diferentes ejercicios tienen por objetivo aterrizar las ideas discutidas en el curso en la cotidianidad de las(os) estudiantes y que a su vez, estas teorías les sirvan de marco para integrar y organizar la información de lo que antes estando "ahí" nada les decía.

Estos ejercicios desarrollan la atención frente a los aspectos de una determinada realidad que reflejen códigos genéricos y la habilidad de hacer continuamente, y en todos los contextos una observación dirigida a entender cómo se manifiestan los patrones genéricos y cuáles implicaciones tienen.

Este interés y habilidad creemos que es el aporte fundamental que este curso puede hacer por su potencial de permanencia después de finalizado, que lleva en muchos casos a seguir analizando roles de género una vez fuera del aula.

En cada curso de Roles se han realizado 3 ó 4 ejercicios, algunos se han repetido en dos trimestres. En total se han experimentado 9 ejercicios diferentes que a continuación describiremos:

\section{1) Diarios}

Desde la primera semana de clases las(os) estudiantes deben llevar un registro diario o interdiario de lo que observan y escuchan en su vida cotidiana que consideran relacionado al tema del curso. ${ }^{6}$ Deben prestar atención a los agentes con que interactúan, sean éstos personas-cosas-sonidos-imágenes- en fin todo estímulo, en que adviertan la presencia de patrones genéricos.

Se recomienda que estén abiertas/os a encontrar infinitas 
manifestaciones de los códigos de género en ellas/os mismos y en lo que (y quienes) les rodea(n). Por ejemplo: las letras de las canciones que escuchan; las imágenes y comentarios que ven en t.v.; en el periódico, libros, artículos, revistas; sus relaciones con diferentes personas (madre, padre, pareja, hijos/as, familiares, amistades, personas relacionadas al trabajo, profesores/as, etc.); comportamiento de hombres y de mujeres en los diferentes lugares que frecuenten. vación.

Todos los aspectos de sus vidas son posibles fuentes de obser-

Los diarios pueden incluir relatos, recortes o fotocopias de material impreso, dibujos o cualquier medio que les resulte conveniente para expresar una idea.

Es imprescindible que toda información que se presente sea comentada, pensada, analizada. Lo que le da el carácter de diario es precisamente el hecho de que debe incluir la reacción personal frente al estímulo que sea. El diario pretende recoger de alguna manera el proceso de toma de conciencia, cambio de actitudes y revalorización que en cuanto a asuntos genéricos la materia debe provocar. De ahí que las dudas, las contradicciones, los "descubrimientos", toda expresión de cómo van manejando las informaciones que están recibiendo sean de vital importancia.

El diario de cada estudiante debe ser algo que hace para sí, para ayudarse a reflexionar y que posteriormente le sirva para entender su proceso. Se hace entrega del diario en la penúltima semana de clase y se les devuelve en la última con comentarios.

Se da a los diarios un valor del 20 al $30 \%$ del curso y se evalúan no en base a las opiniones y actitudes expresadas, sino en base al nivel de análisis y reflexión que reflejen.

Es válido y hasta preferible que se concentren en unos pocos particulares de su interés para que profundicen en en análisis.

\section{2) Análisis de cuentos infantiles desde una perspectiva genérica}

Dado que los cuentos infantiles presentan modelos que influyen en la socialización general de niñas/os, nos interesa analizar el sistema de género en que se desenvuelven las/os personajes de los cuentos elegidos.

En cuanto a lo cualitativo, deben examinarse la psicología, el comportamiento, la interacción y el destino de los/as personajes.

Lo cuantitativo, en cuanto al número de personajes masculinos y al número de personajes femeninos que aparecen es también 
importante. Así como el espacio (número de apariciones y número de líneas o páginas) que se dedica a representantes de cada sexo.

(Ver comentarios de los resultados generales del estudio más adelante en el artículo).

\section{3) Diccionario: definiciones sexistas}

El lenguaje como reflejo y trasmisor de ideología recibe atención particular en la clase de Roles Sexuales. Referir a las/os estudiantes al diccionario de su elección a bsucar el mismo término en sus acepciones masculina y femenina les permite observar el doble código empleado para las definiciones.

El carácter discriminatorio contra las mujeres se hace tan evidente que en algunos casos resulta hasta ridículo y mueve a las/os estudiantes de la risa a la rabia y viceversa.

Aún seguimos recolectando información, que próximamente daremos a conocer.

\section{4) ¿Cómo tu vida sería diferente?}

Este ejercicio consiste en preguntar a niños y niñas: "¿Cómo tu vida sería diferente si mañana al despertar descubrieras ser del otro sexo?" Se formula de manera precisa en función del sexo de quien se esté entrevistando.

¿Tiene por objetivos averiguar cómo se ven los sexos uno al otro? ¿Cuáles consideran las ventajas y privilegios de su sexo y del otro? ¿Cuáles los problemas y limitaciones de cada uno?

Esta técnica sencilla y efectiva para lograr esa información fue diseñada y aplicada por primera vez por las doctoras Alice Baumgartner y Carol Travis en Colorado, Estados Unidos, en 1983.7 Sus resultados y los nuestros se corresponden completamente aunque guardando las especificidades propias de cada cultura.

Los niños hablan de las muchas libertades que perderían; de cómo tendrían que pasar de ser activos a ser pasivos; de cómo estarían obligados a realizar tareas domésticas; de cómo cambiarían sus planes para el futuro en cuanto a estudios y trabajo; y que se preocuparían más por su apariencia. En general les parece un idea "horrible". Las siguientes frases obtenidas en ese pequeศ̃o estudio ilustran lo antes expuesto:

* Yo prefiero ser varón. Los varones son más fuertes que las mujeres. Hacen lo que quieren, mientras que las mujeres tienen que cuidarse. ( 9 ahos).

* Me vuelvo loco. A mí me gusta ser muy hombre. A un niño le dan más libertad. Un niño puede hacer muchas cosas y una niña no. Me mato. (12 años).

* Me sentiría mal porque no podría salir a la calle. (6 años). 
* Cambiaría la forma de vestir y usaría todas las cosas de las mujeres. Pensar, que ahora no voy a enamorarme de las hembras, sino que tendré que esperar que los varones me enamoren. (12 aก̃os).

* Sería horrible, tendría que pasarme la vida fregando y limpiando. (8 años).

* Lo aceptaría si no hay más nada qué hacer. Me pondría después a trabajar y tendría los hijos que vaya a tener. (11 afios).

* Ay! yo prefiero ser niño, las niñas no pueden arreglar computadoras. (7 años).

* Me sentiría nervioso porque quiere decir que tengo que dejarme crecer el pelo, arreglarme las uñas, ir al salón. ( 9 años).

* Dios me libre de una cosa así! Lo único que podría pasar es que coja un cuchillo y me mate. (10 años).

* Eso de ser mujer es un fracaso. (7 años).

* Las mujeres aguantan demasiados golpes. (9 años).

* No me pongo contento no! Me vuelvo a acostar para amanecer varón porque las hembras viven más jugando jueguitos más disparatosos. ( 9 años).

* Me suicidaría, sí yo me suicidaría. (8 años).

Las niñas por su parte respondían en general con entusiasmo, haciendo referencia a la mayor libertad que podrían disfrutar y a una liberación de los quehaceres domésticos. Decían que lamentarían no poder jugar muñecas. Estas son algunas de sus respuestas:

* Me pongo contenta porque los varones juegan mucho y podría mandar en mi casa y hacer cosas con mi primo. (7 años).

* uf! qué, tranquilidad, no tendría que hacer nada y me dejarían salir más. (12 años).

* Me gustaría para no tener que hacer oficios en la casa. ( 9 años).

* Jugaría pelota pero no podría jugar con mis muñecas. (4 años).

* Fuera un poco mejor porque podría ír con mi hermano a todos los lugares que él va y no tendría que estar pidiendo permiso a cada rato. (9 años).

* Seria mejor porque conseguiría trabajo más fácil, mira mi hermano trabaja de limplabotas y gana dinero y yo no puedo. ( 8 aก̃os).

* Le diría a mi papá que me traiga la bicicleta que tengo en Barahona y la montaría en la calle. No tendría que fregar, limpiar y mami, no me mandaría tanto. Estaría todo el tiempo viendo televisión, sin que nadie me moleste. Me pasaría todo el tiempo sentada y no me preocuparía por los regueros. (10 an̂os).

* Si fuera nifio yo podría practicar karate porque me aceptarían a esta edad. (6 años).

* Podría ir al cine sola y decir malas palabras. (8 años).

5) Observación de los juguetes, habitaciones y ropas de nifíos y niñas

Se indicó a las/os estudiantes que seleccionaran una familia 
cualquiera que incluyera al menos un niño y una nin̄a de entre 3 y 12 años de edad, y que en una visita de tiempo no determinado realizaran un ejercicio de observación dirigido a advertir similitudes y diferencias eritre lo perteneciente a los niños y lo perteneciente a las niñas en cuanto a los tres particulares arriba mencionados.

El estudio sistemático de las habitaciones de nif̂os y de niñas como reflejo de la socialización genérica diferenciada en el contexto doméstico fue realizada por primera vez por $\mathrm{H}$. Rheingold y K. Cook en Estados Unidos, 1975."

En nuestra aplicación encontramos francas diferencias entre los sexos en los juguetes, en las habitaciones y en las ropas con que les proveen sus familias. La diferencia se hace más evidente al ir aumentando el nivel socio-económico de la familia, lo cual no nos sorprende en un estudio que se basa en posesiones materiales como indicadores. A mayor riqueza de elementos más se ha podido aplicar el criterio de selección diferenciado.

6) Dibujos de niños y niñas de segundo

y sexto de primaria de ellos/as y

$y$ sus familias presentes y proyectadas

Se le pidió a estudiantes de varias escuelas y colegios que se dibujaran con sus familias de ahora, con quienes ellos/as viven. No se especificó: papá, mamá, hermanos y hermanas para dejar abierta la posibilidad de otros modelos de familia. Luego se pedía que se dibujaran ellos/as "grandes" con sus familias.

Teníamos por objetivo descubrir indicadores gráficos de los códigos genéricos aprendidos.

7) Qué piensan ser cuando grandes: escribirlo y dibujarse

Se trabajó con la misma población del ejercicio anterior. Aún estamos analizando las informaciones de ambos y reuniendo una muestra mayor. Los resultados de esta investigación por ser sorprendentemente reveladores serán presentados en el futuro en otro artículo donde además reproduciremos los dibujos.

\section{8) Momentos y experiencias más felices de la vida}

Los/as estudiantes de Roles Sexuales tenían por tarea preguntar a varias mujeres y hombres de manera individual, que tuvieran 20 años o más, cuáles consideran ellas/os los hechos más felices de sus vidas.

Igual que en los casos anteriores las diferencias entre un sexo y otro, y las similitudes entre personas del mismo sexo 
dejaron en evidencia el doble código genérico, en este caso en cuanto a las valoraciones de las experiencias vividas.

En general, las mujeres se inclinaron por experiencias de carácter "personal" como: primer noviazgo, matrimonio, nacimiento de hijo/a, reencuentro con familiares, etc. Los hombres prefirieron experiencias de trabajo, deportivas, viajes, proezas, etc. Sin embargo, fue de sumo agrado encontrar que muchos hombres reportan su paternidad como causa de gran felicidad.

\section{9) Qué dicen las suegras y los suegros sobre las nueras y los yernos}

Se les preguntó a personas de ambos sexos con hijas e hijos casadas/os, ¿cómo son sus nueras y sus yernos? y ¿qué opinión les merecen cada una/o?

Nuevamente el doble código de apreciación estuvo presente. En la gran mayoría de los casos: las nueras, tanto las suegras como los suegros, las describían en función de qué tan cariñosas, hacendosas y "buenas" fueran, y de qué tan bien "atendieran" a sus hijos y nietos/as. De los yernos se comentaba antes que nada sobre su oficio $u$ ocupación $y$ sobre su ingreso.

Sobre las contrapartidas que dejaban de mencionar dependiendo del sexo, trabajo remunerativo y trabajo/vida doméstica, se les cuestionó específicamente, encontrando que casi todas las nueras trabajaban remunerativamente con un nivel de ingreso correspondiente al de sus maridos y tenían en su mayoría un grado de escolaridad similar al de éstos. Las condiciones de padre y esposo de los yernos se medían en función nuevamente de sus ingresos, y de sus hábitos tóxicos sin más.

El parámetro de medida parece ser para las nueras "cómo son" y para los yernos: "qué hacen"."

Un detalle que nos pareció curioso es que una nuera "buena" le "aguanta" mucho al hijo; pero no entra en la valoración del yerno que tanto le hace "aguantar" a la hija, y ni soñar qué tanto le soporte él a ella.

Es particularmente interesante el caso de una suegra que después de hablar "in extenso" sobre el oficio de su yerno que es vendedor de una ferretería, y sobre lo dulce y suave que es su nuera dio por terminado su testimonio. Se le preguntó entonces si su nuera trabaja fuera de la casa, a lo que contestó secamente: "Sí, ella es doctora, especialista en no sé qué".

En esta ocasión reportaremos con mayor detalle sobre los resultados de uno de los ejercicios realizados por los/as estudiantes 
de Roles Sexuales: Análisis Genérico de Cuentos Infantiles.

El héroe y su premio:

Análisis genérico de cuentos infantiles

Las características de los personajes se corresponden en su mayoría con los estereotipos tradicionales de lo femenino y lo masculino; y como tal son no tan sólo diferentes en función del sexo sino antagónicos entre ellos.

Cualidades altamente valoradas en los personajes femeninos son: la belleza (estereotipada, racista y exclusiva de las mujeres muy jóvenes); la hacendosidad; la pasividad; la conformidad; la generosidad; la obediencia; la debilidad; la ternura. Así lo revelan los propios nombres de los personajes: Blanca Nieves, La Cenicienta, La Princesa Blanca Flor, La Bella, Sonrisa, etc.

De los personajes masculinos se resalta la fortaleza y la osadía. Se espera además que sean aventureros, inteligentes, protectores y astutos. Así son: Juan Sin Miedo, El Sombrerón, La Bestia, El Gigante Egoísta, El Capitán, El Sastrecillo Valiente, etc.

Mientras más características masculinas reúna un personaje femenino más "mala" se le considera. Pero cuando los personajes masculinos reúnen algunas características femeninas en poco grado se les considera "virtuosos", "super-hombres" deseados por todas las doncellas del lugar. Sin embargo, si dan la impresión de "muy femeninos" (comprensivos, tiernos, etc.) son vistos como "débiles" y "poco-hombres"; reforzando así el mito de la polaridad entre los sexos.

Los personajes masculinos son centrales en la trama y los femeninos son secundarios. El triunfo de los personajes masculinos está basado en sus propios esfuerzos, mientras que el de los femeninos consiste en términos generales en "recibir" el amor de un personaje masculino importante deseable por sus estereotípicas características masculinas.

Los personajes masculinos tienen en sus manos desde la subsistencia económica hasta los sueños de los personajes femeninos; dado que para éstas la fórmula mágica de la felicidad consiste en alcanzar el "amor eterno" el día del matrimonio.

Por lo general las decisiones que afectan directamente a los personajes femeninos las toman los personajes masculinos y ellas aceptan con agrado estos gestós de "protección" y de "caballerosidad". Esto se traduce en la pérdida de autonomía de los personajes femeninos a través del reforzamiento del modelo genérico: 
- hombre - dominante, activo, agresor; y mujer - sumisa, pasiva, víctima. Los hombres hacen y ordenan; las mujeres suplican y acatan.

En innumerables libros de cuento, historias y películas se presenta el duelo mortal del Caballero Negro con el Caballero Blanco mientras la Princesa, motivo de la lucha y "objeto" de premio para el vencedor observa angustiada y pasivamente cómo estos dos hombres intentan descuartizarse mutuamente por su amor. Uno caerá al suelo abatido, sino muerto; y el otro, el Caballero "Blanco" (por supuesto) será recibido con emoción por la Princesa quien admirada por su valentía y destreza se rinde en sus poderosos brazos.

No nos sorprendería que si los cuentos continuaran más allá del día de la boda en la mayoría de los casos las agresiones físicas y verbales de estos hombres a estas mujeres fueran el pan nuestro de cada día pues se corresponderían perfectamente con el modelo genérico tradicional arriba mencionado.

Nos parece sumamente peligroso este apareamiento poco sutil que se hace del amor entre hombres y mujeres con la violencia a partir de la idealizada "conquista". Se le enseña a los niños que el amor de una mujer es algo que se logra a partir de su competencia con otros hombres o de convencer al padre de esa mujer de que se es merecedor de la "mano" de su hija por realizar alguna hazaña que sólo tiene valor desde una óptica de machos para demostrar "hombría", como entrar con el castillo del gigante o arrancarle los tres pelos al diablo... en definitiva el deseo de un hombre por una mujer es cosa que se resuelve entre hombres y ella no tiene nada qué opinar.

¡Cómo nos sorprendemos luego de que una "propuesta" de un hombre a una mujer de tener relaciones sexuales que ésta rechace acabe en una violación sexual porque él no acepta un "no" de ella por respuesta! Tendría que venir otro hombre a decir el "no" para que fuera escuchado, y entonces la mujer acabaría agradeciendo a éste su "protección".

A las niñas se les enseña en estas historias a tener una participación real nula, a ser meramente objetos sexuales de los verdaderos protagonistas que son los hombres. A través de los cuales ellas recibirán por asociación su status general en la vida. Son los personajes masculinos en estas historias quienes les dan el sentido a la existencia misma de los personajes femeninos. Ellos son los astros, ellas los satélites decorativos.

Se insiste en las ideas de la competencia entre los hombres y de la envidia entre las mujeres, ambas supuestamente por lograr el amor del otro sexo. 
Se presentan escasas relaciones de amistad entre personajes de distinto sexo, regularmente en las mismas aparece como centro el elemento de interés sexual. Esto parecería absurdo en un material supuestamente producido para niños/as; una contradicción que sólo puede entenderse como producto de la fantasía adulta con toda su complejidad psicológica plasmada con un vocabulario sencillo y coloridas ilustraciones. Si no, cómo podríamos entender que en el $77 \%$ de los 34 cuentos analizados los personajes que llevan la trama son adultos y además miembros/as de la realeza.

En las imágenes de los libros revisados es lo más común ver a los personajes masculinos en actividad (como matando un dragón - rescatando a la princesa de la torre), mientras que los personajes femeninos son mostrados sin hacer nada aparentemente, ni ser productivas en ningún sentido (siempre esperando o sufriendo). Las imágenes, igual que las palabras, nos dicen que lo que los personajes femeninos tienen que "hacer" es "ser" hermosas para consumo de los personajes masculinos.

Adelantamos que en los resultados del ejercicio 7 se observó que en las proyecciones de los niños sobre qué harán cuando grandes, se dibujaban en actividad, ejerciendo la profesión u oficio que escribieron que les gustaría realizar de adultos. Mientras que las niñas se dibujaron en su inmensa mayoría estereotipadamente "preciosas" y sin hacer nada, a pesar de que todas dicen querer ejercer algún oficio a profesión de adultas.

Encontramos entonces que a través de los libros de cuentos infantiles los adultos trasmiten sus concepciones sexistas, racistas y clasistas a niños y niñas. $Y$ presentan un modelo único preconcebido e inflexible de las relaciones de pareja como tema central de un material dirigido a la población infantil.

\section{A modo de conclusión:}

Psicología de los Roles Sexuales obliga a quienes la han cursado a cuestionarse sobre cómo y por qué le cortan las puntas al jamón.

La decisión de si seguirlas cortando o no le corresponde a cada quien. Pero al menos ya se sabe que puede haber otras alternativas de vida como nos sugiere Rosario Castellanos: ${ }^{10}$

Debe haber otro modo

otro modo de ser humano y libre

otro modo de ser.

\section{NOTAS}

1. Esta anécdota se nas refirió como real hace mucho tiempo de fuente que no recordamos. 
2. Citado en "Sex \& Gender: The Human Experience" de James A. Doyle, pág. 5.

3. Alrededor de los 2 años de edad los humanos podemos distinguir sin dificultad la diferencia entre un sexo y otro a partir de los genitales externos y asumir la identidad sexual que nos corresponde. (Jeanne BrooksGunn y Wendy Schempp Matthews, "He \& She: How Children Develop Their Sex-Role Identity", pag. 7).

4. Letty Cottin Pogrebin, "Growing Up Free: Raising Your Child In the 80 ' $\mathrm{s}^{\text {" }}$ pág. 32.

5. James A. Doyle, "Sex \& Gender: The Human Experience" cap. 2. Carol Tavris y Carole wade, "The Longest War: Sex DIfferences In Perspective", cap. 4.

5. Este ejercicio 10 aprendimos del Or. Bruce Carter en su clase de Roles Sexuales en Syracuse University (Otoño 1985).

7. c. Tavris y A. Baungartner, "How would your life be different if you'd been a boy?" Reedbook, Febrero 1983. Citado en "Sex \& Gender" de James A. Doyle, pp. $20-21$.

8. H. Rheingold y K. Cook, "Child Development" 1975, pp. 459-63. Citado en "Sex \& Gender" James Doyle, p. 93.

9. Esto cabe en una tendencia transcultural de valorizar a las mujeres por lo que "son" y a los hombres por lo que "hacen" que expone Nancy Chodorow en su artículo: "Being and Doing: A Cross-Cultural Examination of the Socialization of Males and Females" 1972.

10. Rosario Castellanos de su poema "Meditación en el umbral" que aparece en el libro "Poesía Feminista del Mundo Hispánico" editado por Angel Flores y Kate Flores. Siglo XXI Editores, México, 1984.

\section{BIBLIOGRAFIA}

James A. Doyle. Sex \& Gender: The Human Experience. W.M. C. Brown Publishers, Philadelphia, 1985.

Jeanne Brooks-Gunn y Wendy Schempp Mathews. He \& She: How Children Develop Their Sex-Role Identity. Prentice Hall Inc., New Jersey, 1979.

Letty Cottin P. Growing Up Free: Raising Your Child in the 80's. Bantam Books Inc., New York, 1981.

Carol Tavris y Carole Wade. The Longest War: Sex Differences In Perspectives. Harcourt Brace Javanovich Inc., Florida, 1984.

Nancy Chodorow. "Being and Doing: A cross-cultural examination of the socialization of males and females". Artículo publicado en: Vivian Gornick y Barbara K. Moran, Women In Sexist Society: Studies of Power and Powerlessness. Basic Books Inc., New York, 1971. 


\section{ANEXO 1 \\ PROGRAMA DEL CURSO PSICOLOGIA \\ DE LOS ROLES SEXUALES}

\section{INSTITUTO TECNOLOGICO DE SANTO DOMINGO FACULTAD DE CIENCIAS SOCIALES}

\section{PSICOLOGIA DE LOS ROLES SEXUALES}

PROFESORA: GINNY TAULE PAIEWONSKY OFICINA: GC-102

\section{Objetivos Generales del Curso}

Nos centramos en el análisis de los mitos y verdades sobre las diferencias y similitudes entre los sexos. Examinaremos además la adquisición y desarrollo de los roles de género y los efectos que estos tienen para hombres y mujeres a lo largo de nuestras vidas en todos los niveles.

Serán foco de nuestra atención preguntas tales como:

- ¿Cuáles son las verdaderas diferencias biológicas y psicológicas entre los sexos?

-¿Cómo explican las diferentes teorías la existencia de roles genéricos?

- ¿Qué efectos tiene el sexo y particularmente el género sobre nuestro comportamiento en la edad adulta, tanto en la forma como nos ve la sociedad como en la forma en que nos visualizamos a nosotros(as) mismos(as)?

- ¿Cuáles son las posibilidades de cambios en el sistema de género establecido, a nivel personal y social?

\section{Metodología y Evaluación}

Las clases se desarrollarán articulando cátedras expositivas de la profesora con lecturas, discusiones y ejercicios.

Exámenes: Tendremos un examen de medio término en laclase $\# 9$, y un examen final en la onceava semana. Cada uno con un valor de 30 puntos.

Ejercicios: Deben realizarse 3 ejercicios a lo largo del curso. Las instrucciones precisas para la realización de los mismos las recibirán dos semanas antes de la fecha de entrega correspondiente a cada trabajo. Valor total: 40 puntos.

La asistencia y participación en clases es altamente recomen- 
dada para un mejor aprovechamiento del curso y un rendimiento más eficiente en las evaluaciones.

Las lecturas asignadas para cada unidad son absolutamente necesarias y deben realizarse a tiempo para poder elevar el nivel de las discusiones de clase. De acuerdo a las fechas especificadas en el programa, los materiales a leer se considerarán cubiertos y como tal se les hará referencia en clase y se les evaluará en los exámenes.

Los ejercicios deben ser entregados a tiempo, de lo contrario, la tardanza será penalizada a través de la puntuación.

\section{Contenido del Curso}

I. EXAMINANDO LAS DIFERENCIAS

\section{Clase \#1: Roles de Género en Contexto} Introducción. Diferencias entre sexo y género.

Clase \#2: Estereotipos de Género Prejuicios en el estudio de roles genéricos.

Clase \#3: Diferencias entre los Sexos

Diferencias en atributos y en habilidades (Físicos, Intelectuales y de Personalidad)

II. EXPLICANDO LAS DIFERENCIAS BAJO

LAS DIFERENTES PERSPECTIVAS

Clase \#4: Perspectiva Biológica

Genes, Hormonas, Instintos, Sociobiología.

Clase \#5: Perspectiva Antropológica

Clase \#6: Roles genéricos en diferentes culturas, Relativismo Cultural.

Clase \#7: Perspectiva Sociológica

Clase \#8: Socialización, Agentes Socializadores: Familia

Clase \#9: Examen de Medio Término

Clase \#10: Perspectiva Sociológica

Clase \#11: Sistema Educativo

Clase \#12: Perspectiva Sociológica

Clase \#13: Medios de Comunicación. Lenguaje

Clase \#14: Perspectiva Psicológica

Clase \#15: Teorías Psicológicas sobre el desarrollo de los roles de género: 
-Psicoanálisis

-Conductismo

-Desarrollo Cognitivo

III. TEMAS VARIOS A ANALIZAR DESDE UNA

PERSPECTIVA DE ROLES DE GENERO

Clase \#16: Sexualidad

Clase \#17: Violencia y Agresión

Clase \#18: Ecología, Tecnología y Militarismo

IV. MOVIMIENTOS SOCIALES DE MUJERES Y MOVIMIENTOS SOCIALES DE HOMBRES PARA CAMBIAR LOS PATRONES GENERICOS

Clase \#19: Movimiento Feminista

Clase \#20: Organizaciones de Hombres en Cambio

Clase \#21: Examen Final

\section{LECTURAS ASIGNADAS}

Este listado de lecturas debe ser cumplido puntualmente en correspondencia con el desarrollo del programa. Cualquier modificación de esta selección bibliográfica se comunicará antes de entrar en la unidad a que aplique el cambio.

Para fines de priorizar lecturas por razones de tiempo tengan en cuenta que hay lecturas señaladas como obligatorias y otras como recomendadas.

1. Diferencias entre sexos (Clases \#2 y \#3)

Lectura Obligatoria: "Mitos" S. de Beauvoir (El Segundo Sexo, Tomo II), págs. 181-308.

2. Perspectiva Biológica (Clase \#4)

Lecturas Obligatorias:

"Discursos Falaces Acerca de la Naturaleza de la Mujer" S. Martí y A. Pestana (Sexo, Naturaleza y Poder), págs. 107-172. "La Sociobiología y su Crítica" Charles Frankel (Revista Facetas), págs. 62-69.

"Los Elementos de la Biología" S. de Beauvoir (El Segundo Sexo, Tomo I), págs. 29-60.

3. Perspectiva Antropológica (Clases \#5 y \#6)

Lecturas Obligatorias: 
"Deducciones de estos datos" Margaret Mead (Sexo y Temperamento en las Sociedades Primitivas), págs. 307-351.

"La Diferenciación por Sexo" (Int. a la Antropología Social) Luci Mair, Págs. 59-61.

4. Perspectiva Sociológica. La Familia (Clases \#7 y \#8)

Lecturas Obligatorias:

"Crítica Feminista a la Familia" Marta Lamas (Revista Fem). "Aprendiendo a ser Mujer" M. González, G. Blanco, E. Yglesias (Universidad de Costa Rica).

Revista Quehaceres del CIPAF sobre socialización (septiembre, 1987).

Lectura Recomendada:

"A Favor de las Niñas" E. G. Belotti. Caps. 1, 2 y 3.

5. Perspectiva Sociológica. El Sistema Educativo (Clases \#10 y \#11)

Lecturas Obligatorias:

"Mamá me mima, Papá trabaja". CEDEE.

"A Favor de las Niñas". Elena Gianini Belotti, Cap. 4.

6. Perspectiva Sociológica. Los Medios de Comunicación y el Lenguaje (Clases \#12 y \#13)

Lecturas Obligatorias:

"Medios de Comunicación y Roles de Género". Denise Paiewonsky.

"Lenguaje y Discriminación". Elena Urrutia (Revista Fem)

"Lenguaje y Discriminación Sexual" y "Cómo Evitar el Sexismo en las ilustraciones" (Revista El Sol).

7. Perspectiva Psicológica (Clases \#14 y \#15)

Lecturas Obligatorias:

"El Punto de Vista Psicoanalítico". Simone de Beauvoir 〈El Segundo Sexo, Tomo I), págs. 61-74.

"Mujer Qué Te Lleva a la Locura", por Lore Aresti, Revista Fem No. 32, Feb/Marzo 1984.

Lectura Recomendada:

"Tres Ensayos sobre la Sexualidad" de Sigmund Freud. 
8. Movimientos Sociales para el Cambio Genérico (Clases \#19 y \#20)

Lecturas Obligatorias:

"Definicines de: Mujer, Hombre, Sexualidad, Patriarcado y Sexismo" Victoria Sau (Diccionario Ideológico Feminista").

"¿Qué es el Feminismo?" por Magda Oranich, folleto publicado por el Colectivo Luisa Capetillo, Puerto Rico.

"El Machismo: Mito de la Supremacía Masculina" de Ana Silvia Monzón M. Revista Nueva Sociedad No. 93, Ene/Feb 1988

Las lecturas para las demás clases se asignarán más adelante en el curso. 